\title{
Impact of fibrinogen level on the prognosis of patients with traumatic brain injury: a single-center analysis of 2570 patients
}

\author{
Ke LV ${ }^{\dagger}$, Qiang Yuan ${ }^{\dagger}$, Pengfei Fu, Gang Wu, Xing Wu, Zhuoying Du, Jian Yu, Zhiqi Li and Jin Hu*
}

\begin{abstract}
Background: Fibrinogen may play an important role in the survival of trauma patients; however, its role in traumatic brain injury (TBI) and its correlation with disease prognosis remain poorly understood. The aims of this study were to determine the incidence of TBI-associated hypofibrinogenemia in patients with TBI and to evaluate the prognostic value of fibrinogen level with respect to mortality and clinical outcomes.

Methods: A total of 2570 consecutive TBI patients were retrospectively studied. Prognostic evaluations were determined using the Glasgow Outcome Score (GOS) assessment 3 months after injury. The shape of the relationship between fibrinogen level and mortality or outcome was examined using cubic spline functions. Logistic regression analyses were conducted to identify the association between fibrinogen level and 3-month functional outcomes.

Results: Fibrinogen concentrations $<2 \mathrm{~g} / \mathrm{L}$ were observed in 992 (38.6\%) patients at the time of admission. Multivariate analyses showed that for patients with fibrinogen levels $<2.0 \mathrm{~g} / \mathrm{L}$, those levels were an independent prognostic factor for 3-month mortality (odds ratio [OR], 0.91; 95\% confidence interval [Cl], 0.89-0.93; $P<.001$ ). By contrast, for patients with fibrinogen levels $<2.5 \mathrm{~g} / \mathrm{L}$, the levels were an independent prognostic factor for favorable outcomes at 3 months $(\mathrm{OR}, 1.654 ; 95 \% \mathrm{Cl}, 1.186-2.306 ; P=.003)$. Similar results were also seen for patients with fibrinogen levels $>3.0 \mathrm{~g} / \mathrm{L}$, with the levels being an independent prognostic factor for favorable outcomes at 3 months (OR, 0.771; 95\% Cl, 0.607-0.979; $P=.033)$.

Conclusions: Fibrinogen is an independent prognostic factor for clinical outcomes in TBI patients. Maintaining the level of fibrinogen between 2.5 and $3 \mathrm{~g} / \mathrm{L}$ may improve clinical outcomes in patients with TBI.
\end{abstract}

Keywords: Traumatic brain injury, Fibrinogen, Coagulopathy, Mortality, Outcomes

\section{Background}

Traumatic brain injury (TBI) is a common factor contributing to neurological morbidity and the main cause of disability affecting patient function and quality of life [1]. Coagulopathies play an important role in the progression of intracranial hemorrhage and unfavorable

\footnotetext{
* Correspondence: hujindn@126.com

${ }^{\dagger}$ Ke Lv and Qiang Yuan contributed equally to this work.

Department of Neurosurgery, Huashan Hospital, Fudan University, 12 Wulumuqi Middle Road, Shanghai, China
}

outcomes after TBI [2]. Among the various factors affecting coagulation, fibrinogen is crucial for platelet aggregation, serving as the primary substrate for plasmatic coagulation, resulting in a mesh network used to enhance clot strength [3]. However, despite its importance, fibrinogen remains among the most vulnerable of the coagulation factors in patients sustaining serious injuries. In the early stages of trauma, fibrinogen consumption is increased, but its synthesis remains constant, resulting in critically low levels available $[4,5]$. Beyond this rapid 
consumption, a variety of other causes help contribute to fibrinogen depletion following severe brain trauma, such as blood loss or dilution, consumption, hyperfibrinolysis, hypothermia, and acidosis, thereby further reducing its levels [6-8].

Hypofibrinogenemia is common in trauma patients, including $50-74 \%$ of trauma patients at the time of hospital admission, with levels below $2.29 \mathrm{~g} / \mathrm{L}$ strongly associated with increased mortality $[9,10]$. Juratli et al. reported that pathologic fibrinogen levels can be an independent risk factor for early progressive hemorrhagic injury in TBI patients [11]. In a recent clinical study, 71 of 141 TBI patients with hypofibrinogenemia showed progressive hemorrhagic injury in repeat head CT at $6 \mathrm{~h}$ (50\%) [12]. In addition, low fibrinogen levels are associated with higher risk for elevated intracranial pressure in patients with severe TBI [13]. The European guidelines on management of major bleeding and coagulopathy following trauma recommend treatment with fibrinogen concentrate or cryoprecipitate if major bleeding is accompanied by hypofibrinogenemia [14]. Moreover, when fibrinogen levels in trauma patients fall below $2.29 \mathrm{~g} / \mathrm{L}$, every unit increase in fibrinogen concentration may reduce the mortality of trauma patients by $0.8 \%$ [10]. Although fibrinogen may play an important role in the survival of trauma patients, its role in TBI and its correlation with disease prognosis remain poorly understood [15]. Understanding the predictive ability of fibrinogen in TBI patients at admission will help in the early identification of at-risk patients, resulting in better management and improved prognosis [16].

The aims of our study were two-fold: first, to determine the incidence of TBI-associated hypofibrinogenemia in patients with TBI who were admitted to an adult neurotrauma center, and second, to evaluate the prognostic value of fibrinogen level with respect to mortality and clinical outcomes. To address these aims, we retrospectively investigated the relationship between the fibrinogen levels at the time of admission and clinical outcomes in TBI patients and assessed the optimal target level of fibrinogen which could potentially guide fibrinogen replacement for TBI patients.

\section{Materials and methods Patient population}

A total of 2570 consecutive TBI patients admitted to the Neurotrauma Center between December 2005 and December 2019 were retrospectively studied. The inclusion criteria were as follows: TBI with radiological signs of intracranial brain injury (epidural or subdural hematoma [EDH or SDH], intraparenchymal hemorrhage [IPH], diffuse axonal injury [DAI] or contusion) documented via computed tomography $(\mathrm{CT}) ; \geq 14$ years of age; and admission within $24 \mathrm{~h}$ of TBI. Patients with penetrating brain injuries, preexisting coagulopathy, concurrent use of anticoagulant or antiplatelet agents, and preexisting severe hepatic insufficiency were excluded from the study. All patients were evaluated and treated according to the Guidelines for the Management of Severe Head Injury [17]. Multiple injuries are defined as patients with traumatic injury to a body region other than the brain with an Abbreviated Injury Severity score $\geq 3$. For TBI patients with fibrinogen $<1.5 \mathrm{~g} / \mathrm{L}$, cryoprecipitate or fibrinogen were used to supplement the patient's serum fibrinogen. For patients included retrospectively, an exemption from informed consent was approved by the local Privacy and Data Protection Officer.

\section{Data collection}

Data obtained from TBI patients included age, sex, mechanism of injury, pupillary reaction to light, Injury Severity Score (ISS), Glasgow Coma Scale (GCS) at admission, CT findings, and site of multiple injury. In addition, initial CT scan results taken at the time of admission were used to assess the severity and type of injury. Platelet count and coagulation tests, including international normalized ratio (INR), prothrombin time (PT), and partial thromboplastin time (APTT), were performed, and fibrinogen (FIB) and D-dimer levels were measured, in all patients within $12 \mathrm{~h}$ of injury and assessed at the Central Clinical Chemistry Laboratory using routine laboratory assays. Hemoglobin $(\mathrm{Hb})$ and hematocrit (HCT) levels were also measured and recorded.

The neurological outcomes were determined according to the Glasgow Outcome Score (GOS) as follows: 1 = dead; 2 = vegetative state with an inability to interact with the environment; 3 = severe disability with an inability to live independently but the ability to follow commands; $4=$ moderate disability with the ability to live independently but an inability to return to work or school; and $5=$ good recovery with the ability to return to work or school. Prognostic evaluations were determined using the GOS assessment at 3 months after injury. GOS evaluations were performed by physicians either in person or via telephone. A GOS of 1-3 was categorized as an unfavorable outcome, whereas a score of 4-5 was deemed a favorable outcome.

\section{Statistical analyses}

Continuous variables are expressed as means \pm standard deviations or medians (interquartile ranges), and categorical variables are expressed as percentages. Univariate analyses of categorical data were performed using the chi-square test. Equality of variance was assessed using Levene's test. Normally distributed variables were compared using Student's $t$ test or analysis of variance, whereas non-normally distributed variables were 
compared using the Kruskal-Wallis test or MannWhitney $U$ test. The shape of the relationship between FIB and mortality or outcome was examined using univariate analyses with linear and cubic spline functions. Following univariate analyses, forward stepwise logistic regression analyses were conducted to identify the association between fibrinogen levels and 3-month mortality or functional outcome. The $\mathrm{R}$ statistical package for Windows version 3.3.6 (The R Foundation for Statistical Computing) and SPSS Statistics (version 25.0.0; IBM Corp, Somers, NY, USA) were used to perform the statistical tests. $P$ values $<0.05$ were considered statistically significant. All $P$ values were two-sided.

\section{Results}

A total of 2570 hospitalized adult TBI patients were included in the analyses. The mean age of the patients studied was $48.54 \pm 16.38$ years, of which 1934 patients (73.5\%) were male. The main cause of TBI was traffic accidents $(n=1465,57.0 \%)$, followed by stumbles $(n=$ 45217.6\%) and falls $(n=378,14.7 \%)$. Intraparenchymal hemorrhage and brain contusion were the most common head CT findings $(n=1840,70.2 \%)$. Multiple injuries were seen in 147 (5.7\%) patients. The most common site of multiple injuries was the thorax $(n=103,4.0 \%)$, followed by the extremities $(n=37,1.4 \%)$. The mean ISS of all patients was $15.35 \pm 7.24$. The mean fibrinogen level at admission was $2.54 \pm 1.14 \mathrm{~g} / \mathrm{L}$, with 77 (3.0\%) patients exhibiting fibrinogen levels $<1.0 \mathrm{~g} / \mathrm{L}, 326 \mathrm{pa}-$ tients (12.7\%) with levels between 1.0 and $1.5 \mathrm{~g} / \mathrm{L}, 589$ patients $(22.9 \%)$ between 1.5 and $2.0 \mathrm{~g} / \mathrm{L}, 918$ patients (35.7\%) between 2.0 and $3.0 \mathrm{~g} / \mathrm{L}$, and 660 patients $(25.7 \%)>3.0 \mathrm{~g} / \mathrm{L}$. A total of 198 patients died in this series. The main cause of death was brain death caused by malignant intracranial hypertension $(n=128,64.6 \%)$, followed by multiple organ failure $(n=56,28.3 \%)$, septic shock $(n=11,5.6 \%)$ and intracranial infection $(n=3$, $1.5 \%)$. Among them, $41.9 \%$ died within $24 \mathrm{~h}$ after admission, $24.2 \%$ died between 24 and 48 h, $25.8 \%$ died between 48 and $72 \mathrm{~h}$, and $8.1 \%$ died after $72 \mathrm{~h}$.

Univariate analyses revealed that age, pupillary reactions, GCS at admission, head CT findings, and ISS were significantly related to 3-month mortality. Meanwhile, patients who died exhibited significantly higher INR, PT, APPT, and D-dimer levels, combined with lower FIB, PLT, Hb, and HCT levels relative to those who survived (Table 1). By contrast, age, pupillary reactions, GCS at admission, head CT findings, and ISS were also significantly related to 3-month favorable outcomes (Table 2). Multiple injuries were not significantly related to 3month mortality, although the combination of TBI with either chest or abdominal injuries was significantly associated with 3-month unfavorable outcomes. Patients with an unfavorable outcome exhibited significantly higher INR, PT, APPT, and D-dimer levels, combined with lower FIB, PLT, Hb, and HCT levels compared to those with a favorable outcome.

The shape of the relationship between fibrinogen level and clinical outcomes was examined by univariate analyses with linear and cubic spline functions. The relationship between the fibrinogen level and the probability of favorable outcome and mortality was curvilinear, and the fitting degree of cubic spline functions was higher than that of a linear function. According to the curve correlation between fibrinogen levels and the probability of mortality, we found that when fibrinogen levels were $<2.0 \mathrm{~g} / \mathrm{L}$, mortality was inversely correlated with those levels. However, when they were $>2.0 \mathrm{~g} / \mathrm{L}$, the association between mortality and fibrinogen level was lost. Therefore, fibrinogen levels were divided into two subgroups of $<2.0 \mathrm{~g} / \mathrm{L}$ and $\geq 2.0 \mathrm{~g} / \mathrm{L}$ (Fig. 1). For patients with fibrinogen levels $<2.0 \mathrm{~g} / \mathrm{L}$, the levels were an independent prognostic factor of 3-month mortality in multivariate analyses (odds ratio [OR], 0.91; 95\% confidence interval $[\mathrm{CI}], 0.89-0.93 ; P<.001)$. Age, GCS, pupillary reactions, EDH, and INR were also independent prognostic factors for mortality in this group. The risk of death in patients with fibrinogen levels $<2.0 \mathrm{~g} / \mathrm{L}$ was 0.622 times higher (95\% CI, 0.439-0.882; $P=.008$ ) than that in patients with fibrinogen levels $\geq 2.0 \mathrm{~g} / \mathrm{L}$ (Table 3).

Further analyses of the correlation between fibrinogen levels and the probability of favorable outcomes showed that when the fibrinogen levels were $<2.5 \mathrm{~g} / \mathrm{L}$, the likelihood of favorable outcomes increased in association with fibrinogen level. This positive association was not seen in patients with fibrinogen levels between 2.5 and $3.0 \mathrm{~g} / \mathrm{L}$. Further elevation of fibrinogen to levels $>3.0 \mathrm{~g} / \mathrm{L}$ revealed a decrease in favorable outcomes in association with increases in the levels (Fig. 2). For patients with fibrinogen levels $<2.5 \mathrm{~g} / \mathrm{L}$, the levels were an independent prognostic factor for 3-month favorable outcomes (OR, 1.654; 95\% CI, 1.186-2.306; $P=.003)$. Age, GCS score, D-dimer, SDH, EDH, IPH, brain contusion, and thorax injury were also independent prognostic factors for favorable outcomes in this group. Similarly, for patients with fibrinogen levels $>3.0 \mathrm{~g} / \mathrm{L}$, multivariate analyses showed that the levels were also an independent prognostic factor for 3-month favorable outcomes (OR, 0.771; 95\% CI, 0.607-0.979; $P=0.033$ ), with GCS, Ddimer, IPH, and brain contusions also independent prognostic factors for favorable outcomes in this group (Table 4).

\section{Discussion}

Hypofibrinogenemia is an important indicator of poor prognosis in trauma patients [18]. European guidelines on management of major bleeding and coagulopathy 
Table 1 Summary of patient characteristics and coagulation tests of the dead and surviving patients

\begin{tabular}{|c|c|c|c|c|}
\hline & Died (\%) & Survived (\%) & Total (\%) & $P$ value $^{a}$ \\
\hline N & $198(100.0 \%)$ & $2372(100.0 \%)$ & $2570(100.0 \%)$ & \\
\hline Age (mean \pm SD) & $56.25 \pm 17.81$ & $47.90 \pm 16.10$ & $48.54 \pm 16.38$ & $<.001$ \\
\hline Sex & & & & .391 \\
\hline Male & $154(77.8 \%)$ & $1780(75.0 \%)$ & 1934 (75.3\%) & \\
\hline Female & $44(22.2 \%)$ & $592(25.0 \%)$ & $636(24.7 \%)$ & \\
\hline \multicolumn{5}{|l|}{ Mechanism of injury } \\
\hline Traffic accident & $119(60.1 \%)$ & 1346 (56.7\%) & 1465 (57.0\%) & .090 \\
\hline Fall & 20 (10.1\%) & $358(15.1 \%)$ & $378(14.7 \%)$ & \\
\hline Stumble & $44(22.2 \%)$ & $408(17.2 \%)$ & $452(17.6 \%)$ & \\
\hline Blow to head & $6(3.0 \%)$ & $104(4.4 \%)$ & $110(4.3 \%)$ & \\
\hline Others & $9(4.5 \%)$ & $156(6.6 \%)$ & $165(6.4 \%)$ & \\
\hline \multicolumn{5}{|l|}{ Pupillary reactions } \\
\hline Both reacting & $103(52.0 \%)$ & 2145 (90.4\%) & $2248(87.5 \%)$ & $<.001$ \\
\hline One reacting & $50(25.3 \%)$ & $183(7.7 \%)$ & $233(9.1 \%)$ & \\
\hline None reacting & 45 (22.7\%) & 44 (1.9\%) & $89(3.5 \%)$ & \\
\hline GCS at admission & $6.73 \pm 3.31$ & $11.34 \pm 3.49$ & $10.98 \pm 3.69$ & $<.001$ \\
\hline$\leq 8$ & $145(73.3 \%)$ & $586(24.7 \%)$ & $731(28.5 \%)$ & $<.001$ \\
\hline $9-12$ & $36(18.2 \%)$ & $653(27.5 \%)$ & $689(26.8 \%)$ & \\
\hline $13-15$ & 17 (8.6\%) & 1133 (47.8\%) & 1150 (44.7\%) & \\
\hline \multicolumn{5}{|l|}{$\mathrm{CT}$ findings } \\
\hline IPH or brain contusion & $162(81.8 \%)$ & 1642 (69.2\%) & 1804 (70.2\%) & $<.001$ \\
\hline $\mathrm{SDH}$ & $104(52.5 \%)$ & $684(28.8 \%)$ & $788(30.7 \%)$ & $<.001$ \\
\hline $\mathrm{EDH}$ & $32(16.2 \%)$ & $662(27.9 \%)$ & $694(27.0 \%)$ & $<.001$ \\
\hline DAl & 19 (9.2\%) & $52(2.2 \%)$ & $71(2.8 \%)$ & $<.001$ \\
\hline Multiple body injuries & $13(6.6 \%)$ & $134(5.6 \%)$ & 147 (5.7\%) & .594 \\
\hline Face & $1(0.5 \%)$ & $14(0.6 \%)$ & $15(0.6 \%)$ & 1.000 \\
\hline Thorax & $11(5.6 \%)$ & $92(3.9 \%)$ & 103 (4.0\%) & .333 \\
\hline Abdomen & $2(1.0 \%)$ & $8(0.3 \%)$ & $10(0.4 \%)$ & .385 \\
\hline Extremities & $2(1 \%)$ & $35(1.5 \%)$ & $37(1.4 \%)$ & .828 \\
\hline External & $1(0.5 \%)$ & $3(0.1 \%)$ & $4(0.2 \%)$ & .719 \\
\hline$I S S^{b}$ & $22.33 \pm 6.12$ & $14.77 \pm 7.02$ & $15.35 \pm 7.24$ & $<.001$ \\
\hline INR & $1.16 \pm 0.24$ & $1.06 \pm 0.13$ & $1.07 \pm 0.14$ & $<.001$ \\
\hline PT (s) & $13.44 \pm 2.71$ & 12.161 .55 & $12.26 \pm 1.70$ & $<.001$ \\
\hline APTT (s) & $31.19 \pm 14.65$ & $27.30 \pm 7.20$ & $27.60 \pm 8.09$ & $<.001$ \\
\hline $\mathrm{FIB}(\mathrm{g} / \mathrm{L})$ & $2.06 \pm 1.16$ & $2.58 \pm 1.13$ & $2.54 \pm 1.14$ & $<.001$ \\
\hline D-dimer (mg/L) & $10.52 \pm 14.67$ & $6.90 \pm 10.73$ & $7.18 \pm 11.12$ & $<.001$ \\
\hline $\operatorname{PLT}\left(\times 10^{9} / \mathrm{L}\right)$ & $156 \pm 61$ & $177 \pm 67$ & $176 \pm 67$ & $<.001$ \\
\hline $\mathrm{Hb}(\mathrm{g} / \mathrm{L})$ & $124 \pm 25$ & $131 \pm 21$ & $131 \pm 21$ & $<.001$ \\
\hline HCT (\%) & $36.44 \pm 6.92$ & $38.36 \pm 5.69$ & $38.21 \pm 5.82$ & $<.001$ \\
\hline
\end{tabular}

GCS Glasgow Coma Scale, ISS Injury Severity Score, PLT platelet, INR international normalized ratio, PT prothrombin, APTT activated partial thromboplastin time, FIB fibrinogen, $E D H$ epidural hematoma, $S D H$ subdural hematoma, IPH intraparenchymal hemorrhage, $D A I$ diffuse axonal injury

${ }^{a} P$ values not adjusted for multiple comparisons. Statistical significance determined by chi-square test, Student's $t$ test or Mann-Whitney tests

${ }^{\mathrm{b}} \mathrm{ISS}=\mathrm{AIS}^{2}+\mathrm{AIS}^{2}+\mathrm{AIS}^{2}$, it is the sum of squares for the highest values in each of the three most severely injured body regions 
Table 2 Summary of patient characteristics and coagulation tests of the favorable and unfavorable outcome patients

\begin{tabular}{|c|c|c|c|c|}
\hline & Unfavorable outcome (\%) & Favorable outcome (\%) & Total (\%) & $P$ value $^{a}$ \\
\hline N & $802(100.0 \%)$ & $1768(100.0 \%)$ & $2570(100.0 \%)$ & \\
\hline Age (mean \pm SD) & $52.65 \pm 16.20$ & $46.68 \pm 16.13$ & $48.54 \pm 16.38$ & $<.001$ \\
\hline Sex & & & & .885 \\
\hline Male & $605(75.4 \%)$ & $1329(75.2 \%)$ & $1934(75.3 \%)$ & \\
\hline Female & $197(24.6 \%)$ & $439(24.8 \%)$ & $636(24.7 \%)$ & \\
\hline \multicolumn{5}{|l|}{ Mechanism of injury } \\
\hline Traffic accident & $469(58.5 \%)$ & $996(56.3 \%)$ & 1465 (57.0\%) & .060 \\
\hline Fall & $136(17.0 \%)$ & $242(13.7 \%)$ & $378(14.7 \%)$ & \\
\hline Stumble & $132(16.5 \%)$ & $320(18.1 \%)$ & $452(17.6 \%)$ & \\
\hline Blow to head & $21(2.6 \%)$ & $89(5.0 \%)$ & $110(4.3 \%)$ & \\
\hline Others & $44(5.5 \%)$ & $121(6.8 \%)$ & $165(6.4 \%)$ & \\
\hline \multicolumn{5}{|l|}{ Pupillary reactions } \\
\hline Both reacting & $565(70.4 \%)$ & $1683(95.2 \%)$ & $2248(87.5 \%)$ & $<.001$ \\
\hline One reacting & $160(20.0 \%)$ & $73(4.1 \%)$ & $233(9.1 \%)$ & \\
\hline None reacting & 77 (9.6\%) & $12(0.7 \%)$ & $89(3.5 \%)$ & \\
\hline GCS at admission & $7.55 \pm 3.01$ & $12.54 \pm 2.82$ & $10.98 \pm 3.69$ & $<.001$ \\
\hline$\leq 8$ & $523(65.2 \%)$ & $208(11.8 \%)$ & $731(28.5 \%)$ & $<.001$ \\
\hline $9-12$ & $226(28.2 \%)$ & $463(26.2 \%)$ & $689(26.8 \%)$ & \\
\hline $13-15$ & $53(6.6 \%)$ & $1097(62.0 \%)$ & 1150 (44.7\%) & \\
\hline \multicolumn{5}{|l|}{$\mathrm{CT}$ findings } \\
\hline IPH or brain contusion & $687(85.7 \%)$ & $1117(63.2 \%)$ & 1804 (60.2\%) & $<.001$ \\
\hline $\mathrm{SDH}$ & $361(45.0 \%)$ & $427(24.2 \%)$ & $788(30.7 \%)$ & $<.001$ \\
\hline $\mathrm{EDH}$ & $173(21.6 \%)$ & $521(29.5 \%)$ & $694(27.0 \%)$ & $<.001$ \\
\hline DAl & $50(6.2 \%)$ & $20(1.2 \%)$ & $71(2.8 \%)$ & $<.001$ \\
\hline Multiple body injures & $70(8.7 \%)$ & 77 (4.4\%) & 147 (5.7\%) & $<.001$ \\
\hline Face & $3(0.4 \%)$ & $2(0.7 \%)$ & $15(0.6 \%)$ & .509 \\
\hline Thorax & $57(7.1 \%)$ & $46(2.6 \%)$ & $103(4.0 \%)$ & $<.001$ \\
\hline Abdomen & $6(0.7 \%)$ & $4(0.2 \%)$ & $10(0.4 \%)$ & .014 \\
\hline Extremities & $16(2 \%)$ & $21(1.2 \%)$ & $37(1.4 \%)$ & .158 \\
\hline External & $3(0.4 \%)$ & $1(0.1 \%)$ & $4(0.2 \%)$ & .176 \\
\hline$I S S^{b}$ & $21.5 \pm 6.4$ & $12.57 \pm 5.73$ & $15.35 \pm 7.24$ & $<.001$ \\
\hline INR & $1.10 \pm 0.16$ & $1.06 \pm 0.13$ & $1.07 \pm 0.14$ & $<.001$ \\
\hline PT(s) & $12.59 \pm 1.92$ & $12.11 \pm 1.57$ & $12.26 \pm 1.70$ & $<.001$ \\
\hline APTT(s) & $28.50 \pm 9.62$ & $27.19 \pm 7.26$ & $27.60 \pm 8.09$ & $<.001$ \\
\hline $\mathrm{FIB}(\mathrm{g} / \mathrm{L})$ & $2.45 \pm 1.39$ & $2.58 \pm 1.01$ & $2.54 \pm 1.14$ & .016 \\
\hline D-dimer (mg/L) & $10.97 \pm 15.44$ & $5.46 \pm 7.89$ & $7.18 \pm 11.12$ & $<.001$ \\
\hline $\operatorname{PLT}\left(\times 10^{9} / \mathrm{L}\right)$ & $165 \pm 70$ & $181 \pm 65$ & $176 \pm 67$ & $<.001$ \\
\hline $\mathrm{Hb}(\mathrm{g} / \mathrm{L})$ & $125 \pm 24$ & $133 \pm 20$ & $131 \pm 21$ & $<.001$ \\
\hline HCT (\%) & $36.83 \pm 6.62$ & $38.83 \pm 5.29$ & $38.21 \pm 5.82$ & $<.001$ \\
\hline
\end{tabular}

GCS Glasgow Coma Scale, ISS Injury Severity Score, PLT platelet, INR international normalized ratio, PT prothrombin, APTT activated partial thromboplastin time, FIB fibrinogen, $E D H$ epidural hematoma, $S D H$ subdural hematoma, IPH intraparenchymal hemorrhage, $D A I$ diffuse axonal injury

${ }^{a} P$ values not adjusted for multiple comparisons. Statistical significance determined by chi-square test, Student's $t$ test or Mann-Whitney tests

${ }^{\mathrm{b}} \mathrm{ISS}=\mathrm{AIS}^{2}+\mathrm{AIS}^{2}+\mathrm{AIS}^{2}$, it is the sum of squares for the highest values in each of the three most severely injured body regions 


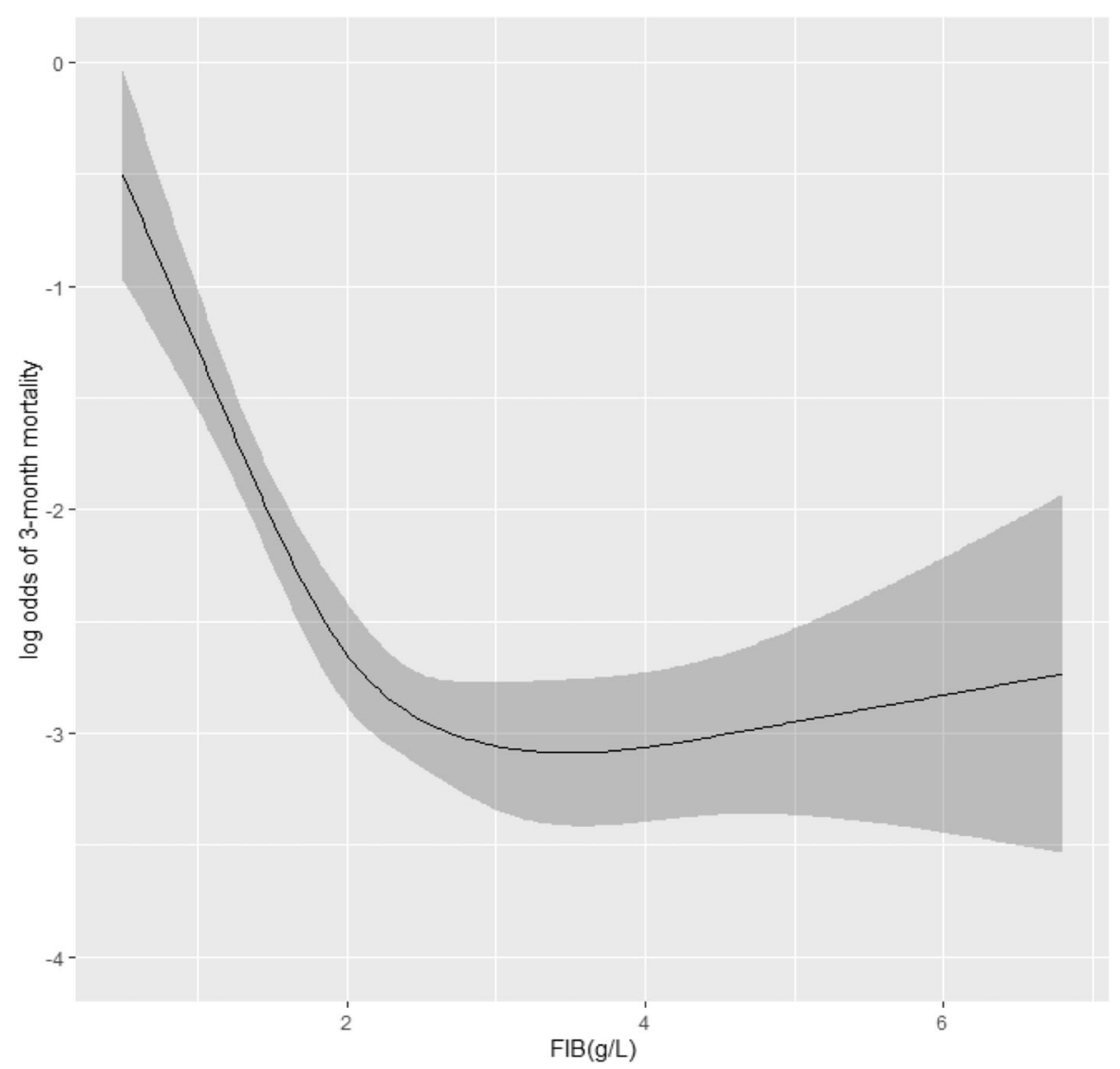

Fig. 1 The shape of the relationship between the fibrinogen level at admission and the probability of 3-month mortality. When fibrinogen levels were $<2.0 \mathrm{~g} / \mathrm{L}$, mortality was inversely correlated with those levels. However, when they were $>2.0 \mathrm{~g} / \mathrm{L}$, the association between mortality and fibrinogen level was lost

Table 3 Correlation between fibrinogen levels and mortality

\begin{tabular}{lcc}
\hline Predictors & OR $(95 \% \mathrm{Cl})$ & \multicolumn{1}{c}{$P$ value $^{a}$} \\
\hline 3-month mortality for patients with fibrinogen level $<\mathbf{2 . 0} \mathbf{g} / \mathbf{L}$ & \\
Age & $1.035(1.019-1.051)$ & $<.001$ \\
GCS & $0.811(0.739-0.891)$ & $<.001$ \\
Pupillary reactions & $2.240(1.467-3.421)$ & $<.001$ \\
EDH & $0.280(0.149-0.526)$ & $<.001$ \\
INR & $4.316(1.556-11.975)$ & .005 \\
FIB & $0.522(0.273-0.995)$ & .048 \\
3-month mortality for patients with fibrinogen level $<\mathbf{2 . 0}$ g/L vs. $\geq \mathbf{2 . 0}$ g/L \\
groups & & \\
AGE & $1.035(1.024-1.047)$ & $<.001$ \\
GCS & $0.760(0.716-0.807)$ & $<.001$ \\
Pupillary reactions & $1.874(1.404-2.500)$ & $<.001$ \\
EDH & $0.399(0.253-0.630)$ & $<.001$ \\
PT & $1.215(1.125-1.312)$ & $<.001$ \\
FIBG & $0.622(0.439-0.882)$ & .008
\end{tabular}

GCS Glasgow Coma Scale, INR international normalized ratio, PT prothrombin, FIB fibrinogen, $E D H$ epidural hematoma, $S D H$ subdural hematoma

${ }^{a} P$ values adjusted for multiple comparisons. Statistical significance determined by multiple logistic regression analysis

${ }^{\mathrm{b}}$ FIBG means patients with fibrinogen level $<2.0 \mathrm{~g} / \mathrm{L}$ or $\geq 2.0 \mathrm{~g} / \mathrm{L}$ groups following trauma recommend the use of fibrinogen concentrate or cryoprecipitate if major bleeding is accompanied by hypofibrinogenemia (viscoelastic signs of a functional fibrinogen deficit or a plasma fibrinogen level $\leq 1.5 \mathrm{~g} / \mathrm{L}$ ) [14]. However, less is known regarding the association between fibrinogen concentration and prognosis in patients with TBI. Therefore, we conducted a retrospective study examining patients over the course of 15 years to better assess the relationship between fibrinogen levels at the time of admission and clinical outcomes in patients with TBI. We found that hypofibrinogenemia is very common in patients with TBI, with $15.7 \%$ of all patients exhibiting fibrinogen levels $<1.5 \mathrm{~g} / \mathrm{L}$, and $38.6 \%$ of patients of patients with levels $<2.0 \mathrm{~g} / \mathrm{L}$.

Our analyses showed that the relationship between fibrinogen levels at the time of admission and the probability of favorable outcome and mortality was not nonlinear but rather curvilinear. When fibrinogen was < $2.0 \mathrm{~g} / \mathrm{L}$, these levels were an independent prognostic factor for 3-month mortality. However, for patients with fibrinogen levels $<2.5 \mathrm{~g} / \mathrm{L}$, multivariate analyses showed 


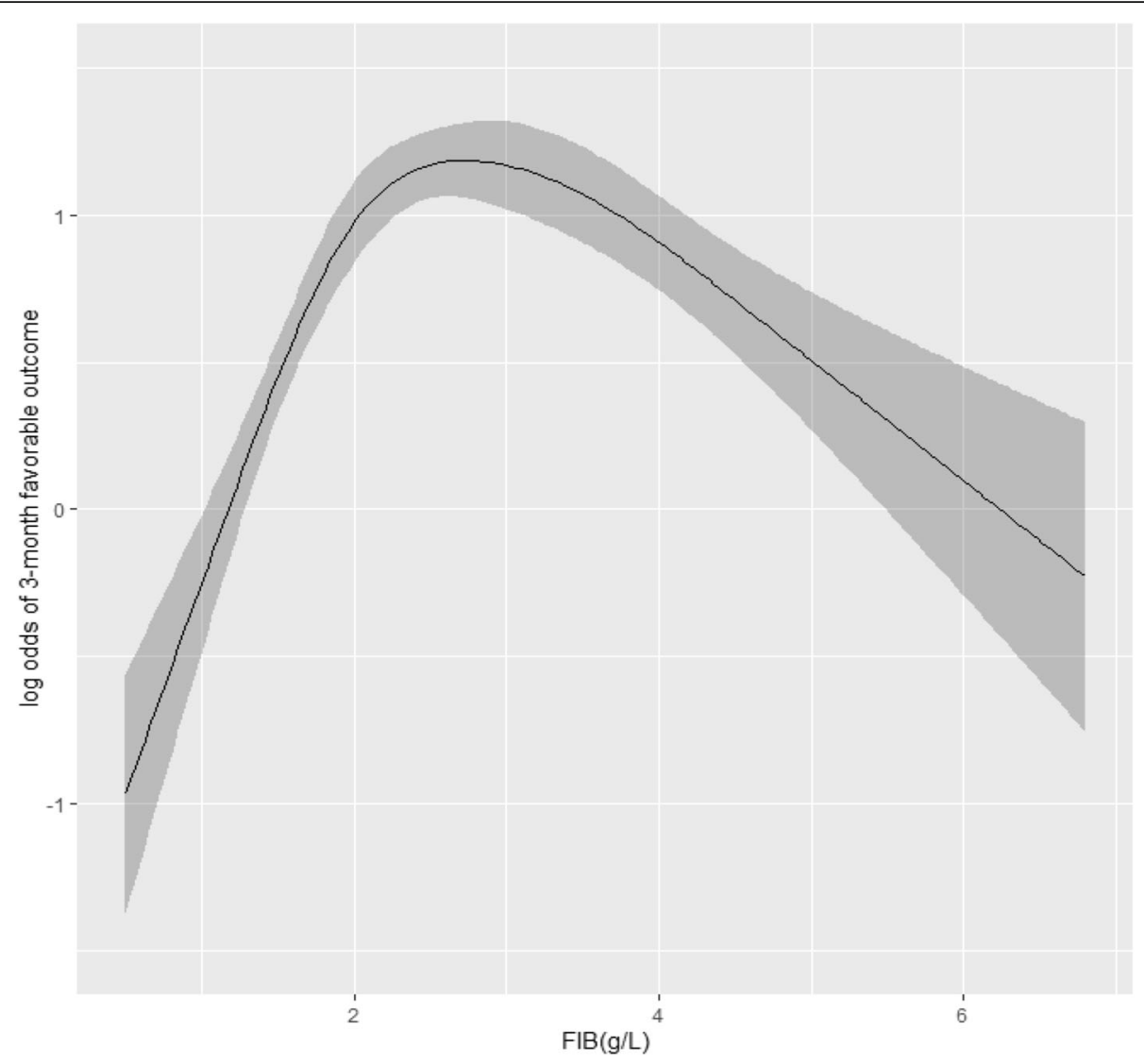

Fig. 2 The shape of the relationship between the fibrinogen level at admission and the probability of 3-month favorable outcome. When the fibrinogen levels were $<2.5 \mathrm{~g} / \mathrm{L}$, the likelihood of favorable outcomes increased in association with fibrinogen level. This positive association was not seen in patients with fibrinogen levels between 2.5 and $3.0 \mathrm{~g} / \mathrm{L}$. Further elevation of fibrinogen to levels $>3.0 \mathrm{~g} / \mathrm{L}$ revealed a decrease in favorable outcomes in association with increases in the levels

that the levels were instead an independent prognostic factor for 3-month favorable outcomes, with the likelihood of a favorable outcome increasing in association with an increase in level.

In addition to showing that low fibrinogen levels increase the risk of poor prognosis, we also provide evidence that a high fibrinogen level itself is a risk factor for poor prognosis. For patients with fibrinogen levels > $3.0 \mathrm{~g} / \mathrm{L}$, multivariate analyses showed that the levels were an independent prognostic factor for 3-month favorable outcomes. The likelihood of a favorable outcome decreased in conjunction with increases in fibrinogen levels. One possible explanation for the increase in unfavorable outcomes in the high fibrinogen group may be due to the role of fibrinogen as an acute-phase protein, indicating the presence of inflammatory diseases, such as atherosclerosis $[18,19]$. In addition, TBI can damage the blood-brain barrier (BBB), causing blood components to extravasate into the brain parenchyma. Studies in different animal models of TBI have demonstrated both acute and delayed BBB damage [20, 21]. Secreted fibrinogen is transformed into fibrin, and releases reactive oxygen species, leading to activation of M1 macrophages and microglia, which may contribute to nerve damage $[22,23]$. In TBI models, damaged axons are an important source of fibrinogen leakage. This localized increase in fibrinogen levels results in microglial cell clustering around damaged blood vessels, which in turn fuels a sustained acute microglial response and induces microglial cells to release reactive oxygen species, thereby causing axonal injury [24, 25]. These findings suggest that plasma levels of fibrinogen should be dynamically monitored in TBI patients prior to FIB supplementation to avoid excessive levels.

Age, GCS, pupillary reactions, EDH, and INR were all independent prognostic factors for mortality in patients with fibrinogen levels $<2.0 \mathrm{~g} / \mathrm{L}$. By contrast, age, GCS score, D-dimer, SDH, EDH, IPH, brain contusion, and thorax injury were all independent prognostic factors for favorable outcomes in patients with fibrinogen levels < $2.5 \mathrm{~g} / \mathrm{L}$, while GCS, D-dimer, IPH, and brain contusion were independent prognostic factors for favorable outcome in patients with levels $>3.0 \mathrm{~g} / \mathrm{L}$. These observations are consistent with previous reports that have 
Table 4 Correlation between fibrinogen levels and the probability of favorable outcomes

\begin{tabular}{llr}
\hline Predictors & OR $(95 \% \mathrm{Cl})$ & $P$ value $^{\mathrm{a}}$ \\
\hline $\begin{array}{l}\text { 3-month favorable outcome for patients with fibrinogen level }<\mathbf{2 . 5} \\
\text { g/L } \\
\text { AGE }\end{array}$ & $0.965(0.955-0.975)$ & $<.001$ \\
GCS & $1.624(1.539-1.714)$ & $<.001$ \\
SDH & $0.601(0.440-0.821)$ & .001 \\
EDH & $1.615(1.124-2.321)$ & .010 \\
IPH or brain contusion & $0.448(0.302-0.665)$ & $<.001$ \\
D-dimer & $0.975(0.964-0.986)$ & $<.001$ \\
FIB & $1.654(1.186-2.306)$ & .003 \\
Thorax injury & $0.509(0.277-0.934)$ & .029
\end{tabular}

3-month favorable outcome for patients with fibrinogen level $>3.0$ $\mathrm{g} / \mathrm{L}$

$\begin{array}{llr}\text { Predictors } & \text { OR }(95 \% \mathrm{Cl}) & P \text { value }^{\mathrm{a}} \\ \text { GCS } & 1.555(1.450-1.668) & <.001 \\ \text { IPH or brain contusion } & 0.446(0.246-0.808) & .008 \\ \text { D-dimer } & 0.932(0.899-0.966) & <.001 \\ \text { FIB } & 0.771(0.607-0.979) & .033\end{array}$

GCS Glasgow Coma Scale, FIB fibrinogen, EDH epidural hematoma, SDH subdural hematoma, $I P H$ intraparenchymal hemorrhage

${ }^{a} P$ values adjusted for multiple comparisons. Statistical significance determined by multiple logistic regression analysis

indicate that ISS score is an indicator of clinical outcomes in patients with severe trauma. Floccard et al. also reported that FIB levels in trauma patients at the time of admission could be affected by ISS [26]. In our study, logistic regression analyses demonstrated no significant association between ISS and clinical outcomes in TBI patients. However, multivariate regression analyses did identify significant correlations, with strong associations between thoracic injury, as assessed by AIS score, and clinical outcomes in TBI patients with fibrinogen levels $<2.5 \mathrm{~g} / \mathrm{L}$. TBI patients who also suffered thoracic injury exhibited a 1.96-fold increase in unfavorable outcomes compared to patients with no such injury. This result is consistent with our previous findings that thoracic injury is frequent in patients with TBI and is closely related to TBI outcomes. Moreover, we found that thoracic injury remains the most frequent injury, accounting for $70 \%$ of all secondary injuries in TBI patients.

In traumatic hemorrhage, the amplifying mechanism in the early stage of coagulation causes a surge in thrombin production [27]. Fibrinogen is converted into fibrin under the action of thrombin, which leads to the consumption of fibrinogen [28]. Studies in tissue injury demonstrate that endothelial injury accelerated fibrinogen generation and triggered hyperfibrinolysis [29]. Thrombin generation response to trauma combined the effects of hyperfibrinolysis further aggravate fibrinogen loss [30]. This may also explain why nearly $40 \%$ of TBI patients suffer from hypofibrinogenemia. However, the relationship between thrombin and fibrinogen in consumptive coagulopathy needs to be further studied.

Utilizing serum biomarker to early diagnose hypofibrinogenemia has the potential to overwhelm the adverse prognosis in TBI patients. Serum fibrinogen concentration is the most direct evidence of fibrinogen deficiency in patients with TBI. Additional biomarkers included plasma levels of antithrombin, protein C, APTT, and head CT scan [31]. Our data demonstrate that fibrinogen might be a valuable serum biomarker to differentiate TBI patients with hypofibrinogenemia from acute traumatic coagulopathy, as well as to potentially guideline fibrinogen supplementation during acute trauma care.

Some limitations of our study should be acknowledged. All analyses were performed retrospectively. While the large sample size was a strength, all subjects were recruited from a single neurotrauma center and the time of patient enrollment became relatively large (14 years). A well-designed multicenter, prospective, randomized clinical trial is needed to achieve more accurate results. Second, this study excluded patients who received blood product transfusions prior to admission but did not take into account the dilutional effect of the volume of the fluid given before arriving at the emergency room. To reduce this effect, the results of the first FIB test at the time of admission were studied. However, it is difficult to ensure standardized timing for the collection of blood samples, which may introduce some variability into the first fibrinogen concentration. Third, we only studied the relationship between fibrinogen at the time of admission and prognosis. Whether fibrinogen was supplemented during hospitalization or perioperative period and relevant data were not recorded. Finally, the Marshall CT scan scores of patients involved in our study are extremely hard to obtain because of the long period of patient enrollment time.

\section{Conclusions}

In conclusion, we observed fibrinogen concentrations < $2 \mathrm{~g} / \mathrm{L}$ in $38.6 \%$ of TBI patients at the time of admission, with this level strongly related to an increased inhospital mortality. Comparisons of fibrinogen levels and clinical outcomes suggested that maintaining fibrinogen levels between 2.5 and $3.0 \mathrm{~g} / \mathrm{L}$ may be the best way to improve prognosis, although further prospective studies are needed to confirm these observations.

\section{Abbreviations}

TBI: Traumatic brain injury; GCS: Glasgow Coma Scale; GOS: Glasgow Outcome Score; ISS: Injury Severity Score; PLT: Platelet; INR: International normalized ratio; PT: Prothrombin; APTT: Activated partial thromboplastin time; Hb: Hemoglobin; HCT: Hematocrit; FIB: Fibrinogen; EDH: Epidural hematoma; SDH: Subdural hematoma; IPH: Intraparenchymal hemorrhage; DAl: Diffuse axonal injury 


\section{Acknowledgments}

The authors would like to thank Dr Ruiyi Sun and Dr Jiang Fang for their useful comments during the preparation of the manuscript.

\section{Authors' contributions}

Study concept and design: K.L., Q.Y., and J.H. Drafting of the manuscript: K.L. Statistical analysis: K.L. and Q.Y. Interpretation of data: K.L. and Q.Y. Critical revision of the manuscript for important intellectual content: J.H., G.W., and F.F. Administrative, technical, or material support: Y.D., J.Y., and Q.L. Supervision: J.H. and X.W. The author(s) read and approved the final manuscript.

\section{Funding}

The funding was provided by the National Natural Science Foundation of China (NSFC Grants 81701206 to Q.Y. and 81471241 to X.W.) and the National Natural Science Foundation of China (NSFC Grants 81870968 and 81671200 to J.H.).

\section{Availability of data and materials}

The datasets used or analyzed during the current study are available from the corresponding author on reasonable request.

\section{Ethics approval and consent to participate}

Not applicable

\section{Consent for publication}

Not applicable.

\section{Competing interests}

The authors declare that they have no competing interests.

Received: 23 July 2020 Accepted: 27 August 2020

Published online: 25 September 2020

\section{References}

1. Maegele M, Schochl H, Menovsky T, Marechal H, Marklund N, Buki A Stanworth S. Coagulopathy and haemorrhagic progression in traumatic brain injury: advances in mechanisms, diagnosis, and management. Lancet Neurol. 2017;16(8):630-47.

2. Carrick MM, Tyroch AH, Youens CA, Handley T. Subsequent development of thrombocytopenia and coagulopathy in moderate and severe head injury: support for serial laboratory examination. J Trauma. 2005;58(4):725-9 discussion 729-730.

3. Sorensen B, Larsen OH, Rea CJ, Tang M, Foley JH, Fenger-Eriksen C. Fibrinogen as a hemostatic agent. Semin Thromb Hemost. 2012:38(3):268-73.

4. Martini WZ, Chinkes DL, Pusateri AE, Holcomb JB, Yu YM, Zhang XJ, Wolfe RR. Acute changes in fibrinogen metabolism and coagulation after hemorrhage in pigs. Am J Physiol Endocrinol Metab. 2005;289(5):E930-4.

5. Martini WZ, Holcomb JB. Acidosis and coagulopathy: the differential effects on fibrinogen synthesis and breakdown in pigs. Ann Surg. 2007;246(5):831-5.

6. Kobayashi T, Terao T, Maki M, Ikenoue T. Diagnosis and management of acute obstetrical DIC. Semin Thromb Hemost. 2001;27(2):161-7.

7. Fagon JY, Chastre J, Novara A, Medioni P, Gibert C. Characterization of intensive care unit patients using a model based on the presence or absence of organ dysfunctions and/or infection: the ODIN model. Intensive Care Med. 1993;19(3):137-44.

8. Waterstone M, Bewley S, Wolfe C. Incidence and predictors of severe obstetric morbidity: case-control study. BMJ. 2001;322(7294):1089-93 discussion 1093-1084.

9. Schlimp CJ, Voelckel W, Inaba K, Maegele M, Ponschab M, Schochl H. Estimation of plasma fibrinogen levels based on hemoglobin, base excess and Injury Severity Score upon emergency room admission. Crit Care. 2013; 17(4):R137.

10. Hagemo JS, Stanworth S, Juffermans NP, Brohi K, Cohen M, Johansson PI, Roislien J, Eken T, Naess PA, Gaarder C. Prevalence, predictors and outcome of hypofibrinogenaemia in trauma: a multicentre observational study. Crit Care. 2014:18(2):R52.

11. Juratli TA, Zang B, Litz RJ, Sitoci KH, Aschenbrenner U, Gottschlich B, Daubner D, Schackert G, Sobottka SB. Early hemorrhagic progression of traumatic brain contusions: frequency, correlation with coagulation disorders, and patient outcome: a prospective study. J Neurotrauma. 2014 31(17):1521-7.

12. Fair K, Farrell D, McCully B, Rick E, Dewey EN, Hilliard C, Dean R, Lin AL, Hinson HE, Barbosa RR, et al. Fibrinolytic activation in patients with progressive intracranial hemorrhage after traumatic brain injury. J Neurotrauma. 2019

13. Kiyohira M, Suehiro E, Fujiyama Y, Suzuki M. Predictive factors of intracranial pressure elevation in patients with severe acute subdural hematoma. No Shinkei Geka. 2019;47(7):753-60.

14. Spahn DR, Bouillon B, Cerny V, Duranteau J, Filipescu D, Hunt BJ, Komadina $R$, Maegele M, Nardi G, Riddez L, et al. The European quideline on management of major bleeding and coagulopathy following trauma: fifth edition. Crit Care. 2019;23(1):98

15. Lissitchkov T, Madan B, Djambas Khayat C, Zozulya N, Ross C, Karimi M, Kavakli K, De Angulo GR, Almomen A, Schwartz BA, et al. Efficacy and safety of a new human fibrinogen concentrate in patients with congenital fibrinogen deficiency: an interim analysis of a Phase III trial. Transfusion. 2018;58(2):413-22.

16. Spahn DR, Spahn GH, Stein P. Indications and risks of fibrinogen in surgery and trauma. Semin Thromb Hemost. 2016;42(2):147-54.

17. Carney N, Totten AM, O'Reilly C, Ullman JS, Hawryluk GW, Bell MJ, Bratton SL, Chesnut R, Harris OA, Kissoon N, et al. Guidelines for the management of severe traumatic brain injury, Fourth Edition. Neurosurgery. 2017:80(1):6-15

18. Schultz DR, Arnold PI. Properties of four acute phase proteins: C-reactive protein, serum amyloid A protein, alpha 1-acid glycoprotein, and fibrinogen. Semin Arthritis Rheum. 1990;20(3):129-47.

19. Corrado E, Rizzo M, Coppola G, Fattouch K, Novo G, Marturana I, Ferrara F, Novo $S$. An update on the role of markers of inflammation in atherosclerosis. J Atheroscler Thromb. 2010;17(1):1-11.

20. Sarani B, Dunkman WJ, Dean L, Sonnad S, Rohrbach Jl, Gracias VH. Transfusion of fresh frozen plasma in critically ill surgical patients is associated with an increased risk of infection. Crit Care Med. 2008;36(4):1114-8.

21. Stinger HK, Spinella PC, Perkins JG, Grathwohl KW, Salinas J, Martini WZ, Hess JR, Dubick MA, Simon CD, Beekley AC, et al. The ratio of fibrinogen to red cells transfused affects survival in casualties receiving massive transfusions at an army combat support hospital. J Trauma. 2008;64(2 Suppl):S79-85 discussion S85.

22. Davalos $D$, Akassoglou K. Fibrinogen as a key regulator of inflammation in disease. Semin Immunopathol. 2012;34(1):43-62

23. Ryu JK, Petersen MA, Murray SG, Baeten KM, Meyer-Franke A, Chan JP, Vagena E, Bedard C, Machado MR, Rios Coronado PE, et al. Blood coagulation protein fibrinogen promotes autoimmunity and demyelination via chemokine release and antigen presentation. Nat Commun. 2015;6:8164

24. Davalos D, Ryu JK, Merlini M, Baeten KM, Le Moan N, Petersen MA, Deerinck TJ, Smirnoff DS, Bedard C, Hakozaki H, et al. Fibrinogen-induced perivascular microglial clustering is required for the development of axonal damage in neuroinflammation. Nat Commun. 2012;3:1227.

25. Merlini M, Rafalski VA, Rios Coronado PE, Gill TM, Ellisman M, Muthukumar G, Subramanian KS, Ryu JK, Syme CA, Davalos D, et al. Fibrinogen induces microglia-mediated spine elimination and cognitive impairment in an Alzheimer's disease model. Neuron. 2019;101(6):1099-108 e1096.

26. Floccard B, Rugeri L, Faure A, Saint Denis M, Boyle EM, Peguet O, Levrat A Guillaume C, Marcotte G, Vulliez A, et al. Early coagulopathy in trauma patients: an on-scene and hospital admission study. Injury. 2012;43(1):26-32.

27. Roberts HR, Hoffman M, Monroe DM. A cell-based model of thrombin generation. Semin Thromb Hemost. 2006;32(Suppl 1):32-8.

28. Scheraga HA. The thrombin-fibrinogen interaction. Biophys Chem. 2004; 112(2-3):117-30

29. Hunt BJ, Jurd KM. Endothelial cell activation. A central pathophysiological process. BMJ. 1998;316(7141):1328-9.

30. Brohi K, Cohen MJ, Ganter MT, Schultz MJ, Levi M, Mackersie RC, Pittet JF. Acute coagulopathy of trauma: hypoperfusion induces systemic anticoagulation and hyperfibrinolysis. J Trauma. 2008;64(5):1211-7 discussion 1217.

31. Charbit B, Mandelbrot L, Samain E, Baron G, Haddaoui B, Keita H, Sibony O, Mahieu-Caputo D, Hurtaud-Roux MF, Huisse MG, et al. The decrease of fibrinogen is an early predictor of the severity of postpartum hemorrhage. J Thromb Haemost. 2007;5(2):266-73.

\section{Publisher's Note}

Springer Nature remains neutral with regard to jurisdictional claims in published maps and institutional affiliations. 